\title{
Influence Of Rubber Bearing Isolation Technology On Buildings With Different Periods
}

\author{
Ye Wang ${ }^{1,}$,, Xiaosheng Song ${ }^{1, b}$ \\ ${ }^{1}$ North China University of technology, Tangshan City, Hebei, China \\ a1301776523@qq.com, bsong-xs@163.com
}

Keywords: rubber bearings, isolated structures, buildings with different periods

\begin{abstract}
At present, rubber bearing isolation technology has been widely used in the design of isolation structure at home and abroad. Its core idea is to increase the vibration cycle of the building by increasing rubber isolation bearing, so as to reduce the damage to the superstructure by the seismic action. As a breakthrough, this paper focuses on the impact of rubber bearing isolation technology on different cycle buildings, including the interlayer displacement and the vibration period of the superstructure. In recent decades, with the rapid development of rubber bearing isolation technology, it has not only been used in engineering, but also produced huge economic effects in actual production. In this paper, PKPM software has been used to establish different periods of the building structure model, and the following works have been carried out:
\end{abstract}

1) a summary of rubber isolation bearing.

2) the design of the superstructure of the isolated building.

3) according to the demand of research contents, the upper frame structure of isolation layer is designed.

4) through the analysis of the interlayer displacement and periodic variation of different periods of buildings, the overall influence of rubber bearings on different periods of buildings is explored.

\section{Introduction}

In recent years, such as the Tangshan earthquake in 1976, it instantly destroyed Tangshan, a city with a population of over million, resulting in about about 400000 of casualties and 30 billion yuan in the tragic loss. Nearly 70000 people were killed and 400 thousand injured in the "5.12" earthquake that broke out in Wenchuan. At the same time, it also caused a lot of housing damage, road damage, landslides and many economic losses caused by dammed lakes. so how to effectively reduce the loss caused by earthquakes has become the main research direction of all countries.

\section{Basic outline and principle of structure}

Principle of base isolation dynamics. Generally speaking, isolation technology mainly applies the idea of "softness and rigidity". Based on the base isolation, the seismic response of the structure is reduced by changing the horizontal lateral stiffness of the isolation layer to adjust the horizontal lateral stiffness $\mathrm{K}$ and the damping value $\mathrm{C}$ by changing the horizontal lateral stiffness of the isolation layer. According to the basic principle of dynamics, the general dynamic differential equation of structure is: 


$$
M \alpha_{s}+C \alpha_{s}+K x_{s}=F(t)-M
$$

Upper middle: $\mathrm{M}, \mathrm{C}$ and $\mathrm{K}$ represent the mass matrix, damping matrix and stiffness matrix of the structure respectively.; The role of $F(t)$ as an external incentive to the structure; $; x_{s}$ are acceleration responses, velocity responses and displacement responses, respectively, when the structure is subjected to external excitation, and is the ground earthquake acceleration. It is easy to analyze from the upper formula that the acceleration, velocity and displacement responses of a structure can not be changed by people. However, we can artificially control the seismic responses of structures by controlling the quality of structures $\mathrm{M}$, the damping of structures $\mathrm{C}$, the stiffness of structures $\mathrm{K}$ and the magnitude of external excitation $\mathrm{F}(\mathrm{t})$. The idea of isolation design is to reduce the seismic response of the superstructure and achieve the purpose of damping by changing the damping $\mathrm{C}$ and stiffness $\mathrm{K}$ of the structure.

Laminated rubber bearing. Rubber material is a material with low elasticity and large deformation capacity. While the steel plate is a material with high elasticity and small deformation, the laminated rubber isolation bearing formed by the combination of steel plate and rubber not only has great deformation ability, but also can bear a lot of load, so it is very suitable for application in isolation structure. This is because when the bearing is subjected to vertical pressure, the rubber layer will deform along the radial direction. Because the existence of the steel plate will restrain the deformation of the rubber layer, the vertical bearing capacity of the bearing is very high. In this paper, the isolation layer is based on the circular rubber isolator.

High damping laminated rubber bearing. In common rubber materials, a special material is added. Graphite is commonly used. A suitable amount of graphite can make the rubber have certain damping property, and adjust the damping by adjusting the amount of graphite added. At present, the use of high damping laminated rubber bearing is still less in China. The production of this kind of product is mainly abroad, and the actual project is mainly used in bridge engineering. After repeated loading tests on high damping rubber isolation bearing, Shen Zhaoyong, Zhou Fulin and Cui Jie found that the horizontal equivalent stiffness and the equivalent damping ratio decreased with the increase of shear strain, but increased when the loading pressure increased. In addition, it is found that the high damping rubber bearing can withstand large ultimate shear deformation, and the bearing will have hardening when large deformation occurs.

\section{Structural design}

General situation of project design. This project is the student dormitory building in Tangshan area. The earthquake resistant category of the building is the key fortification class. There is no basement, the first layer is 3.6 meters high, and the height of two layers and above is $3.0 \mathrm{~m}$. The aseismic buildings are 6 storey and 12 storey reinforced concrete frame structures with a design life of 50 years. The seismic fortification category is the key fortification class, which should be higher than the seismic fortification intensity of the local area, and the seismic grade of the 6 and 12 layer cast-in-place reinforced concrete frame is two and one. The maximum impact coefficient of the horizontal earthquake is 0.16 , the period reduction coefficient is 0.65 . The adjustment coefficient of the life load of floor and roof is 1 , the standard value of the living load of the civil building floor is 2 , the floor area of the floor beam is more than 25 square meters, the reduction coefficient of the floor live load is 0.9 , the base depth is 1.5 meters.

Basic parameters of project design. The seismic fortification intensity of the building site is 8 degrees, and the basic seismic acceleration is $0.20 \mathrm{~g}$.

The site type of this project is $I_{1}$, the site characteristic period is $0.25 \mathrm{~s}$, and the design seismic grouping is second groups. 
By using isolation technology, the horizontal seismic design of the upper structure can be reduced by one and a half and 7 degrees $(0.15 \mathrm{~g})$. The aim is to increase the safety reserve of the structure, and to ensure that the superstructure is not affected by the small scale earthquake, and the safety and comfort of the building are improved.

Superstructure design scheme. The project structure icon quasi layer is as follows, the area of the project is 378 , the plane size is $25.2 \mathrm{~m} \mathrm{x} 15 \mathrm{~m}$, the $\mathrm{X}$ direction is 6 span, the span is $4200 \mathrm{~mm}$, the $Y$ direction is 3 span, the span is $6300 \mathrm{~mm}, 2400 \mathrm{~mm}, 6300 \mathrm{~mm}$, the height of the first layer is $3.6 \mathrm{~m}$, the rest is $3 \mathrm{M}$, and the same standard layer and the different height of the four building models are established.

1) 6 storey frame structure, the base isolation structure is isolated, the first floor thickness is $160 \mathrm{~mm}$, and the first layer thickness of the non isolated structure is $140 \mathrm{~mm}$.

2) 12 storey frame structure, the base isolation structure is isolated, the first floor thickness is $160 \mathrm{~mm}$, and the first floor thickness of the non isolated structure is $140 \mathrm{~mm}$.
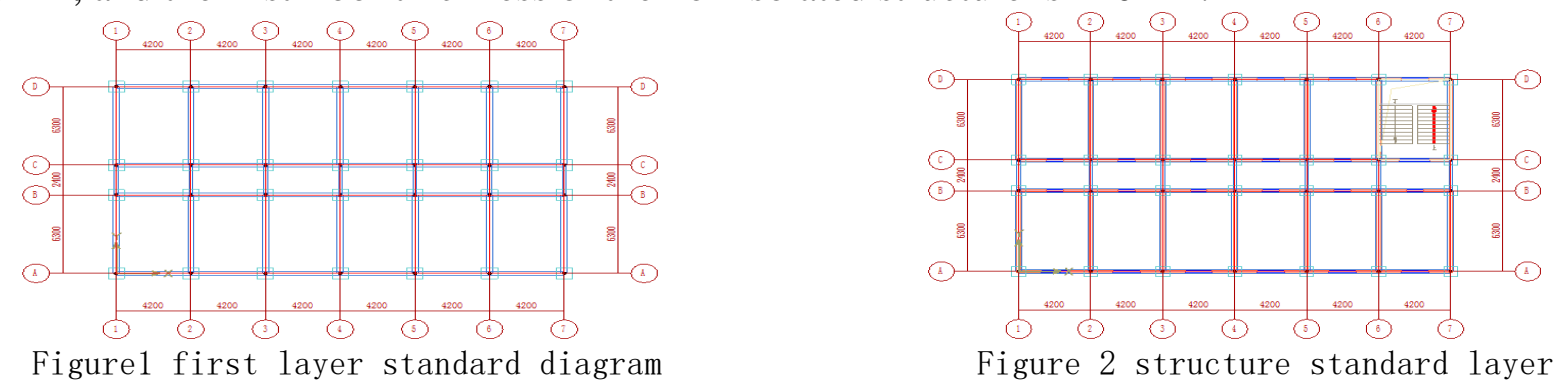

This project adopts PKPM to analyze the non isolated structure model. Among them, the natural vibration period (seconds), X, Y direction translational and torsional coefficients of multi-storey and high-rise concrete structures are as follows: (choose 6 modes):

Table 1 Comparison of multi-layer and high rise concrete model structure

\begin{tabular}{|c|c|c|c|c|c|c|}
\hline \multirow{2}{*}{$\begin{array}{c}\text { Vibration } \\
\text { model }\end{array}$} & \multicolumn{3}{|c|}{ High rise concrete structure } & \multicolumn{3}{c|}{ Multi-layer concrete structure } \\
\cline { 2 - 7 } & cycle & $\begin{array}{c}\text { Translational } \\
\text { coefficient }(\mathrm{x}+\mathrm{y})\end{array}$ & $\begin{array}{c}\text { Torsional } \\
\text { coefficient }\end{array}$ & cycle & $\begin{array}{c}\text { Translational } \\
\text { coefficient }(\mathrm{x}+\mathrm{y})\end{array}$ & $\begin{array}{c}\text { Torsional } \\
\text { coefficien }\end{array}$ \\
\hline 1 & 0.8420 & $1.00(1.00+0.00)$ & 0.00 & 0.4191 & $1.00(1.00+0.00)$ & 0.00 \\
\hline 2 & 0.7103 & $0.96(0.00+0.96)$ & 0.04 & 0.3447 & $0.87(0.00+0.87)$ & 0.08 \\
\hline 3 & 0.6384 & $0.04(0.00+0.04)$ & 0.96 & 0.3185 & $0.13(0.00+0.13)$ & 0.92 \\
\hline 4 & 0.2732 & $1.00(1.00+0.00)$ & 0.00 & 0.1388 & $1.00(1.00+0.00)$ & 0.00 \\
\hline 5 & 0.2207 & $0.90(0.00+0.90)$ & 0.10 & 0.1123 & $0.84(0.00+0.84)$ & 0.12 \\
\hline 6 & 0.2052 & $0.10(0.00+0.10)$ & 0.90 & 0.1056 & $0.16(0.00+0.16)$ & 0.89 \\
\hline
\end{tabular}

Isolation layer design. Through the analysis of the upper structure and the geological environment, I set the isolation layer on the foundation of the foundation and below the first floor, and the arrangement of the isolation bearing should be determined according to the following principles.

1) the plane layout of the isolation bearing should correspond to the plane position of the vertical stress component in the superstructure and the substructure. The rubber isolation bearing should be set in a large force, and the spacing should not be too large. Its specifications, quantity and 
distribution should be calculated and determined according to the requirements of the vertical bearing capacity, lateral stiffness and damping[1].

2) the wind resistant devices installed in the isolation layer should be arranged symmetrically and dispersedly at the periphery of the building.

3 ) the location of the isolation components should be taken for easy inspection and replacement except for the calculation.

4) the top surface of the isolation bearings with different specifications should be designed at the same elevation.

Selection and arrangement of isolation bearings. This project is a class B building. When selecting isolation bearings, the following conditions shall be met:

1) the ultimate horizontal displacement of the isolation bearing under compressive stress should be less than 0.55 times of the effective diameter and the larger value of two times of the total rubber thickness of the bearing within two[1].

2) after the durable test of the corresponding design datum period, the stiffness and damping characteristics of the isolation bearing are not more than $20 \%$ of the initial value, and the Xu variable is not more than $5 \%$ of the total rubber thickness inside the support[1].

3 ) the vertical compressive stress of the rubber bearing should not exceed $12 \mathrm{Mpa} 11]$.

The isolation bearings adopted in this project have four models, N400G4 ,N500G4,N600G4 and N700G4, and the specific performance indexes of the isolation bearings are shown in Table 2:

Table 2 Summary of isolation support information

\begin{tabular}{c|c|c|c|c}
\hline \multirow{2}{*}{$\begin{array}{c}\text { Type of } \\
\text { isolation bearing }\end{array}$} & \multicolumn{2}{|c|}{ Multi-layer structure support } & \multicolumn{2}{c}{ High rise structure support } \\
\cline { 2 - 5 } & N400G4 & N500G4 & N600G4 & N700G4 \\
\hline $\begin{array}{c}\text { Shear modulus of } \\
\text { elasticity ( } \mathrm{MPa})\end{array}$ & 0.392 & 0.392 & 0.392 & 0.392 \\
\hline $\begin{array}{c}\text { One time } \\
\text { form factor }\end{array}$ & 24.3 & 24 & 28.5 & 33.3 \\
\hline $\begin{array}{c}\text { Secondary } \\
\text { shape factor }\end{array}$ & 5.84 & 5.1 & 5.45 & 6.36 \\
\hline $\begin{array}{c}\text { Vertical } \\
\text { stiffness } \mathrm{kN} / \mathrm{m}\end{array}$ & $1.348 \mathrm{e}+006$ & $1.42 \mathrm{e}+006$ & $2.282 \mathrm{e}+006$ & $3.632 \mathrm{e}+006$ \\
\hline $\begin{array}{c}\text { Horizontal } \\
\text { stiffness } \mathrm{kN} / \mathrm{m}\end{array}$ & 710 & 760 & 990 & 1350 \\
\hline $\begin{array}{c}\text { Number of } \\
\text { bearings }\end{array}$ & 8 & 20 & 8 & 20 \\
\hline
\end{tabular}

Basic Information of Structural Components. The material model of each component of this project is shown in Table 2. According to the "Seismic Design Code for Buildings" 3.9.2 Structural Material Performance Requirements:

1) Concrete strength grades, frame beams, frame pillars, and earthquake-resistant grades are frame beams, columns, and cores of the first-class framework, which should not be lower than C30; structural columns, core columns, ring beams, and other structural components are not Should be lower than C20[1].

2) Frames and diagonal bracing members (including stair sections) with seismic resistance ratings of grades I, II, and III. Where the longitudinal reinforcement steel is made of normal steel, the ratio of the measured tensile strength of the reinforcement to the measured yield strength should not be less than 1.25; The ratio of the measured value of the yield strength of the steel bar to the standard 
value of the yield strength shall not be greater than 1.3, and the measured value of the total elongation of the steel bar under the maximum tensile force shall not be less than 9\%[1].

Table 3 Material grades of building structural member

\begin{tabular}{l|l|l|l|l|l}
\hline $\begin{array}{l}\text { Standard } \\
\text { layer }\end{array}$ & $\begin{array}{l}\text { Plate } \\
\text { thickness }(\mathrm{mm})\end{array}$ & $\begin{array}{l}\text { concrete } \\
\text { strength }\end{array}$ & $\begin{array}{l}\text { Thickness of protective } \\
\text { layer(mm) }\end{array}$ & $\begin{array}{l}\text { Rebar } \\
\text { category }\end{array}$ \\
\hline 1 & 160 & C30 & 15 & HRB400 \\
\hline 2 & 140 & C30 & 15 & HRB400 \\
\hline 3 & 140 & C30 & 15 & HRB400 \\
\hline 4 & 140 & C30 & 15 & HRB400 \\
\hline
\end{tabular}

Building structural load design parameters. This project is a student dormitory building. According to the "Loading Code for Building Structures", the live load requirements are uniformly distributed on the civil building floor. The standard value of the living load on the student dormitory floor is $2 \mathrm{kN} / \mathrm{m}^{2}$, including corridors, entrance halls, and people Roofing and so on. According to Table E5, when the architectural design period is 50 years in Tangshan, the wind load and snow load are $0.4 \mathrm{kN} / \mathrm{m}^{2}$ and $0.35 \mathrm{kN} / \mathrm{m}^{2} 0$. In order to reduce the weight of the frame structure, aerated concrete hollow blocks are used as the wall inside and outside the project. Its bulk density is $6 \mathrm{kN} / \mathrm{m}^{2}$, the first floor height is 3.6 meters, the beam height is 0.5 meters, and the wall thickness is 0.2 meters. Since the window area does not exceed one half of the wall area, the wall load on the beam is not reduced, and it is designed as a structural safety reserve. Therefore, the load on the beam is $6 \times(3.6-0.5) \times 0.2=3.72 \mathrm{kN} / \mathrm{m}$, take $4 \mathrm{kN} / \mathrm{m}$, and the upper line load of the second floor and above beam is $3.5 \mathrm{kN} / \mathrm{m}[2]$.

\section{Architectural design requirements for seismic isolation:}

1) The height-to-width ratio of the structure should be less than 4 and should not be larger than the specific provisions of the non-isolated structure in the relevant specifications. The deformation characteristics are close to the shear deformation, and the maximum height should meet the requirements of the non-isolated structure in this specification; the aspect ratio When the structure specified in the relevant regulations for the structures larger than 4 or non-isolated structures is designed for seismic isolation, special studies should be conducted[1].

2) The construction site should be type I, II, III, and the type of foundation with good stability should be selected[1].

3) The total horizontal force generated by standard values of wind loads and other non-seismic horizontal loads should not exceed $10 \%$ of the total structural gravity[1].

4) The seismic isolation layer shall provide the necessary vertical bearing capacity, lateral stiffness and damping; the piping and wiring of equipment passing through the isolation layer shall adopt flexible connection or other effective measures to adapt to the rare earthquake level of the isolation layer [1].

Seismic wave selection. According to the "Code for Seismic Design of Buildings" (Section 5.1.2), the input seismic acceleration time history curve should be correctly selected to meet the requirements of the three elements of ground motion, namely, the spectral characteristics, effective peak value and duration must all comply with the regulations. 
Table 4 Seismic Response Analysis of Building Structure Input Wave

\begin{tabular}{c|c|c|c|c|c}
\hline $\begin{array}{c}\text { Seismic } \\
\text { wave name }\end{array}$ & $\begin{array}{c}\text { Seismic wave } \\
\text { properties }\end{array}$ & $\begin{array}{c}\text { Main direction } \\
\text { Peak } \\
\text { acceleration }\end{array}$ & $\begin{array}{c}\text { Secondary peak } \\
\text { acceleration }\end{array}$ & $\begin{array}{c}\text { Vertical peak } \\
\text { acceleration }\end{array}$ & duration \\
\hline RH1TGO25 & Artificial wave & 100 & 100 & 100 & 20 \\
TH001TG025 & Actual wave & 116.8 & 113.7 & 48.7 & 43.98 \\
TH002TG025 & Actual wave & 261.8 & 258.1 & 123.3 & 28.48 \\
\hline
\end{tabular}

\section{Analysis of data before and after isolation of frame structure}

\section{Analysis of Interlayer Displacement of Structures.}

Table 5 Comparison of interlayer displacement of isolated structure models under rare earthquakes

\begin{tabular}{r|c|c}
\hline $\begin{array}{c}\text { Numb } \\
\text { er }\end{array}$ & $\begin{array}{c}\text { Average displacement of multilayer } \\
\text { isolated structure }(\mathrm{mm})\end{array}$ & $\begin{array}{c}\text { Average displacement of high rise } \\
\text { isolated structure }(\mathrm{mm})\end{array}$ \\
\hline 1 & 16.3 & 25.0 \\
\hline 2 & 176.5 & 316.5 \\
\hline 3 & 175.8 & 314.9 \\
\hline 4 & 175.9 & 315.4 \\
\hline 5 & 177.2 & 316.3 \\
\hline 6 & 178.1 & 316.7 \\
\hline 7 & 178.2 & 317.1 \\
\hline
\end{tabular}

It can be seen from the above table that under the action of rare earthquake artificial wave RH1TG025, the average displacement of layer number 1 is $16.3 \mathrm{~mm}$, and the average displacement of layer number 2 to 7 is gradually increased from $175.8 \mathrm{~mm}$ to $178.2 \mathrm{~mm}$; In the isolated frame structure, the average displacement of layer number 1 is $25.0 \mathrm{~mm}$, and the average displacement of layer numbers 2 to 7 is gradually increased from $314.9 \mathrm{~mm}$ to $317.1 \mathrm{~mm}$. Because the elevation of layer number 1 is positive or negative, the average displacement is much different from the average displacement of the above layers. Layers 2 to 7 are the top plates of each layer, and the average displacement is almost the same, so the upper structure is close to translation; It can be compared with multi-story isolated buildings, with an average displacement of 1 to 7 layers in tall buildings. Similarly, the average displacement of layer 1 in the high-rise isolation structure is very different from the average displacement of the other layers. It can be seen from the comparison of the above table that in the case of the same seismic wave and the isolation layer, the higher the height of the building structure, the greater the displacement between the layers; but in the same structure of the upper layer or the multilayer, the layers above the layer number 1 The difference in average displacement between layers is small, indicating that when an earthquake is encountered, it is an overall displacement with no rigid displacement. 
Table 6 Comparison of $\mathrm{x}$-direction interlayer displacement of seismic structures with different periods under rare earthquakes

\begin{tabular}{c|c|c}
\hline Number & $\begin{array}{c}\text { Multi-layer seismic structure } \\
\text { displacement }(\mathrm{mm})\end{array}$ & $\begin{array}{c}\text { High-rise seismic structure } \\
\text { displacement }(\mathrm{mm})\end{array}$ \\
\hline 1 & 1.2 & 1.17 \\
\hline 2 & 2.3 & 2.07 \\
\hline 3 & 4.12 & 4.16 \\
\hline 4 & 5.78 & 6.33 \\
\hline 5 & 7.14 & 8.42 \\
\hline 6 & 8.10 & 10.39 \\
\hline 7 & 8.66 & 12.22 \\
\hline
\end{tabular}

According to the comparative analysis in Table 6 above, under the rare earthquake, the average interlayer displacement increases step by step, and the difference between the maximum displacement and the minimum displacement is larger than that of the isolated structure. Significantly increased, indicating that the higher the floor, the greater the building sway, the stronger the earthquake; the higher the average floor displacement increases with the increase of the floor compared to the multi-storey building.

Structural cycle analysis.

Table 7 periodic comparison of isolated structure models under rare earthquakes

\begin{tabular}{c|c|r|r|r}
\hline \multirow{2}{*}{$\begin{array}{l}\text { Modal } \\
\text { number }\end{array}$} & \multicolumn{2}{|l|}{$\begin{array}{l}\text { Multi-layer seismic isolation } \\
\text { structure }\end{array}$} & \multicolumn{2}{|c}{$\begin{array}{l}\text { High-rise isolation } \\
\text { structure }\end{array}$} \\
\cline { 2 - 5 } & Cycle $(\mathrm{s})$ & Frequency & Cycle $(\mathrm{s})$ & Frequency \\
\hline 1 & 2.8337 & 0.3529 & 3.2731 & 0.3055 \\
\hline 2 & 2.8333 & 0.3530 & 3.2709 & 0.3057 \\
\hline 3 & 0.1850 & 5.4060 & 0.2019 & 4.9541 \\
\hline 4 & 0.1637 & 6.1069 & 0.1633 & 6.1231 \\
\hline 5 & 0.0996 & 10.0374 & 0.1552 & 6.4441 \\
\hline 6 & 0.0967 & 10.3417 & 0.1026 & 9.7481 \\
\hline 7 & 0.0910 & 10.9858 & 0.0980 & 10.2018 \\
\hline 8 & 0.0810 & 12.3520 & 0.0970 & 10.3116 \\
\hline 9 & 0.0791 & 12.6421 & 0.0902 & 11.0828 \\
\hline 10 & 0.0781 & 12.8007 & 0.0794 & 12.5940 \\
\hline 11 & 0.0687 & 14.5614 & 0.0784 & 12.7507 \\
\hline 12 & 0.0588 & 17.0171 & 0.0715 & 13.9792 \\
\hline & & & & \\
\hline
\end{tabular}

For comparison, the modal number of high-rise isolated structures is approximately equal to the modal number of multi-storey isolated structures. The comparison analysis of the above table shows that the cycle of the multilayer isolation structure is obviously smaller than that of the high-rise isolation structure, the frequency is larger than the high-rise isolation structure, the floor of the multilayer or high rise isolation structure is from low to high, the cycle gradually decreases, the higher the height, the slower the period, the higher the frequency, the higher the height and the smaller the frequency increase. . Therefore, under the same isolation layer and earthquake, the cycle of high rise 
isolation structure is larger than that of multilayer isolation structure, the higher the height, the closer to the same period; the frequency of the multilayer isolation structure is obviously larger than the frequency of the high-rise isolation structure, the higher the height, the faster the frequency.

Table 8 Comparison of the seismic model of the earthquake in the rare earthquake

\begin{tabular}{l|l|l}
\hline $\begin{array}{c}\text { Modal } \\
\text { number }\end{array}$ & \multicolumn{1}{c|}{$\begin{array}{c}\text { Multi-layer seismic structure } \\
\text { cycle }(\mathrm{s})\end{array}$} & High-rise seismic structure cycle \\
\hline 1 & 0.4191 & 0.8420 \\
\hline 2 & 0.3447 & 0.7103 \\
\hline 3 & 0.3185 & 0.6384 \\
\hline 4 & 0.1388 & 0.2732 \\
\hline 5 & 0.1123 & 0.2207 \\
\hline 6 & 0.1056 & 0.2052 \\
\hline 7 & 0.0814 & 0.1553 \\
\hline 8 & 0.0638 & 0.1197 \\
\hline 9 & 0.0613 & 0.1140 \\
\hline 10 & 0.0576 & 0.1059 \\
\hline 12 & 0.0514 & 0.0827 \\
\hline
\end{tabular}

The comparison of the previous table shows that the cycle of the multilayer seismic structure is less than the period of the high-rise seismic structure, the frequency is larger than the high-rise seismic structure; the floor of the multilayer or high rise isolation structure decreases from low to high, and the higher the height, the less the cycle decreases, the higher the frequency, the higher the height, the smaller the frequency increase. It can be seen that under the same isolation layer and earthquake, the cycle of the high-rise seismic structure is greater than that of multi story seismic structure. The higher the height, the smaller the period, the faster the frequency, the more the frequency of the vibration per second, the more intense the earthquake.

Through the comparative analysis of Table 6 and Table 7, it is found that the natural vibration period of the multi-layer seismic structure is $0.4191 \mathrm{~s}$, the natural vibration period of the structure after isolation is $2.8337 \mathrm{~s}$, and the extension is nearly 7 times; the natural vibration period of the high-rise seismic structure is $0.8420 \mathrm{~s}$. After the isolation, the natural vibration period of the structure is $3.2731 \mathrm{~s}$, which is extended by 3.88 times. The period of the isolated structure is significantly larger than the period of the seismic structure, indicating that the isolation layer can extend the period, avoid the natural period of the site, and reduce the generation of resonance phenomena, thus ensuring the safety of the structure.

\section{Displacement checking calculation of isolation bearing}

According to the "code for seismic design of buildings" (GB50011-2010) 12.2.6, the rubber isolation bearing should not exceed 0.55 times the effective diameter of the support and the smaller value of the total rubber thickness of the support 3 times two times. 
Table 9 Seismic deformation verification of seismic isolation bearings

\begin{tabular}{c|c|c|c|c}
\hline Type of & Model of & Maximum & Permissible & Satisfied or no \\
\hline \multirow{2}{*}{$\begin{array}{c}\text { Multi-layer rare } \\
\text { earthquake }\end{array}$} & N400G4 & 178.2 & 220 & YES \\
\cline { 2 - 5 } & N500G4 & 178.2 & 275 & YES \\
\hline \multirow{2}{*}{$\begin{array}{c}\text { High-rise rare } \\
\text { earthquake }\end{array}$} & N600G4 & 317.1 & 330 & YES \\
\cline { 2 - 5 } & N700G4 & 317.1 & 385 & YES \\
\hline
\end{tabular}

\section{Conclusion}

In this paper, two identical multilayer frame structures and two identical high-rise frame structures are established by using PKPM software. Through elastoplastic time history analysis, one of the two identical structures is arranged for isolation layer to compare the interlayer displacement, acceleration and period, and the following conclusions can be obtained.

1) after the base isolation, the period of the structure has been prolonged by 4-5 times, and the damage to the building is greatly reduced by the earthquake action. After the isolation, the horizontal displacement of the structure is concentrated in the isolation layer, and the base shear and the interlayer acceleration are greatly reduced, and the structure is moved as a whole.

2) the self vibration period of the structure can be prolonged obviously, which can avoid the resonance effect of the structure and the site, greatly reduce the failure probability of the frame structure and reduce the shear stress of the structure, even if the horizontal earthquake force of each column is reduced, the shear stress is reduced.

3) under the circumstances of many earthquakes, we can draw the conclusion that the parameters of the structure after the seismic isolation are better than those before the seismic isolation by loading artificial waves and comparing the seismic and base isolation structures by the elastoplastic time history analysis method. When the earthquake comes, the interlayer displacement and deformation of the isolated structure occur in the isolation layer, and the relative displacement between the layers above the isolation layer is very small and the whole is almost translational, so the isolation layer can effectively filter the damage to the superstructure by the seismic action.

4) to sum up, the rational layout of the isolation bearing can not only improve the integrity of the structure, but also ensure the safety of the structure and personnel in the specified range, and the "small earthquake, the moderate earthquake repair, the large earthquake can not be reversed" to be truly converted to "large earthquake repairable".

\section{References}

[1] Ministry of Housing and Urban-Rural Development of the People's Republic of China.GB 50011 - 2010 Building seismic design specifications [S].Beijing : China Architecture\& Building Press, 2010.

[2] Ministry of Housing and Urban-Rural Development of the People's Republic of China.GB 50009 -2012 Building structure load gauge building structure [S].Beijing: China Architecture\& Building Press, 2012. 